\title{
THE EFFECTS OF PRE-BOND MOISTURE ON THE FRACTURE BEHAVIOUR OF ADHESIVELY-BONDED COMPOSITE JOINTS
}

\author{
B.R.K. BLACKMAN*, B.B. JOHNSEN, A.J. KINLOCH \& W.S. TEO \\ Department of Mechanical Engineering, Imperial College London, South Kensington \\ Campus, London SW7 2AZ. UK. \\ (* Contact: b.blackman@imperial.ac.uk)
}

Keywords: Adhesive joints, Pre-bond moisture, Fracture toughness, Glass-transition, Surface morphology

\begin{abstract}
The results of an investigation into the effects of pre-bond moisture absorbed by fibrecomposite substrates prior to bonding with various structural epoxy adhesives are presented. Substrates were bonded in the as-received condition (where substrates had been exposed to atmospheric moisture for periods of greater than three months) and were also bonded in the fully-dried condition (after drying under vacuum at $105{ }^{\circ} \mathrm{C}$ for 28 days). Additionally, substrates were conditioned by water submersion for various durations prior to bonding. Double cantilever beam tests were performed on the resulting joints to determine the adhesive fracture energy, $G_{\mathrm{IC}}$. The effect of pre-bond moisture on the glass transition temperature of the adhesive was also determined. One adhesive was shown to exhibit an extreme sensitivity to pre-bond moisture. A severe reduction in fracture energy accompanied a change in the fracture morphology and $\mathrm{T}_{\mathrm{g}}$. Other adhesives were shown to be relatively insensitive to the levels of pre-bond moisture introduced.
\end{abstract}

\section{Introduction}

The deleterious effects of exposing adhesive joints to hostile environments have been well documented in the literature, e.g. [1-3]. Many of these studies have shown that exposure to moisture can lead to very significant reductions in joint strength and frequently to a change in the locus of joint failure from cohesive in the adhesive, to interfacial between the adhesivesubstrate interface. However, there have been relatively few studies into the effects of moisture present in the substrate (or in the adhesive) at the time of manufacturing the joint. Whilst the issue of pre-bond moisture in the substrates is clearly not significant for metallic substrates, it is important for joints formed between polymeric-composite substrates where 
appreciable levels of moisture may be absorbed before bonding. According to Hart-Smith [46] the existence of pre-bond moisture in or on the adhesive, or absorbed within a pre-cured laminate, has been a significant problem.

The motivation for the study reported here was the discovery of a pronounced substrate dependence in the fracture behaviour of adhesively-bonded joints in a round-robin test programme during the development of the British Standard BS7991 [7]. Values of the adhesive fracture energy, $G_{\mathrm{IC}}$, had been determined using the adhesively-bonded double cantilever beam (DCB) and tapered double cantilever-beam (TDCB) test specimens using three different substrate materials: a unidirectional carbon-fibre reinforced thermosetting matrix polymer (CFRP) laminate, an aluminium alloy and mild steel. The substrate dependence highlighted in this study is shown in Figure 1, which reveals the values of $G_{\text {IC }}$ measured in joints bonded with either CFRP or mild steel substrates using the same generalpurpose epoxy-paste adhesive. The results from five participating laboratories are shown and it was evident that the adhesive fracture energy was up to five times greater when mild steel, as compared to CFRP, substrates were employed. All substrates had been surface treated to ensure that interfacial effects were not observed during fracture, all failure was cohesive in approximately the centre of the adhesive layer, the bondline thickness was always $0.40+/-$ $0.05 \mathrm{~mm}$ and the deformation of the substrates was always elastic such that any effects of plastic deformation of the substrates could be ruled out. Subsequent research $[8,9]$ revealed that pre-bond moisture in the composite substrates, that diffused into the adhesive during the manufacture of the joint, was the root cause of this substrate dependence.

In the present paper, the common sources of pre-bond moisture and their effects on the performance of adhesively bonded composites are briefly reviewed. The results of an investigation into the effects of pre-bond moisture on the fracture behaviour of joints between CFRP substrates bonded with a number of different structural epoxy adhesives are then discussed. In a subsequent paper [10], the results of a detailed investigation into the fracture mechanisms of the very moisture-sensitive adhesive will be presented.

\section{Sources and effects of pre-bond moisture}

There are several potential sources of pre-bond moisture in composite substrates and their effects can be cumulative and very significant. Perhaps the most obvious source of pre-bond moisture is from the atmosphere; and such moisture can enter the joint either via the 
polymeric substrates prior to joint manufacture, or via the adhesive. Most polymers will absorb atmospheric moisture to some extent and the more hydrophilic of these, e.g. nylon may absorb up to $15 \%$ by weight of water (\% w/w) [11]. Carbon-fibre reinforced epoxy composites will typically absorb $0.5-1.0 \% \mathrm{w} / \mathrm{w}$ of atmospheric moisture if maintained at typical laboratory conditions (i.e. $23^{\circ} \mathrm{C}, 55 \% \mathrm{RH}$ ). Highly polar, or treated surfaces may also attract atmospheric moisture rapidly if there is a delay between the surface treatment and the adhesive being applied. In addition, the highly polar molecules of an adhesive will attract water. This is a particular problem when adhesive film is stored in a freezer, as condensation will form as it is warmed to room temperature prior to joint manufacture- a problem which is acknowledged in industry, where guidelines state that rolls of film-adhesive are to be stored in sealed moisture-barrier bags which are to be left, unopened, for 16 hours at ambient conditions before use. Also, tubs of paste adhesives may absorb atmospheric moisture if left uncovered, and some moisture may enter paste adhesive-dispenser cartridges, especially if removed from cold storage and allowed to attain ambient temperature in moist air. Finally, sometimes water is added deliberately by the formulator to modify the rheological properties of paste adhesives.

A few studies have reported on the effects of pre-bond moisture on the subsequent mechanical properties of the cured adhesive joint; where the moisture has diffused from the substrates into the adhesive during joint manufacture and so affected the adhesive's properties. For example, Sage and Tiu [12] reported a 'bubble problem' in bonded joints when composite substrates were employed. Severe voiding in the adhesive layer reduced the joint strength and this was traced to water vapour being emitted from the composite substrates during joint manufacture. Drying the composite or curing the bonded joints under isostatic pressure were found to prevent the formation of voids in these joints. Similar problems were reported by Parker [13] where the absorption of atmospheric moisture by composite substrates had significantly reduced joint strength. Three possible effects of pre-absorbed moisture in the composite were identified as: (i) voiding, (ii) plasticization of the adhesive, and (iii) a reduction in interfacial adhesion. Which of these actually occurred depended upon the adhesive used. Parker found that drying composite substrates (which only contained moderate levels of absorbed pre-bond moisture) at $70^{\circ} \mathrm{C}$ or $150^{\circ} \mathrm{C}$ prior to bonding was very effective. However, drying substrates with higher moisture contents at $180^{\circ} \mathrm{C}$ induced blistering of the composite. The implications for repairing composite structures using adhesively-bonded patches were also considered, and this issue was investigated in more 
detail by Robson et al. [14]. This study found that low levels of pre-bond moisture (below about $0.5 \% \mathrm{w} / \mathrm{w}$ ) had little effect on the strength of adhesively-bonded repairs, but as the moisture content increased, so the repair strength fell and the volume fraction of voids in the adhesive layer increased with increasing levels of pre-bond moisture in the composite substrates.

Moisture accumulation by film adhesives during freezer storage and the effects on joint strength was studied extensively by Dodiuk et al. [15, 16], and the effects on the bulk adhesive properties were studied by Buchman et al. [17]. Pre-bond moisture absorbed by a film adhesive was invariably associated with a reduction in subsequent joint strength. This was found to be largely reversible for low levels of moisture content (up to about $0.3 \% \mathrm{w} / \mathrm{w}$ ). However, above this level, damage occurred to the adhesive that could not be reversed by drying the adhesive film under vacuum. Thus, the deleterious effects of water on the cured bulk adhesive properties were mostly reversible at low levels but irreversible at higher levels of moisture content.

More recently, van Voast et al. [18, 19] has reported the effects of pre-bond humidity exposure of composites on the fracture toughness and morphology of bonded composite joints. Three different $177^{\circ} \mathrm{C}$ curing adhesives were studied and moisture was introduced into the composite substrates prior to bonding via different levels and durations of humidity exposure. Moisture contents of up to $1.3 \% \mathrm{w} / \mathrm{w}$ were attained, although a level of $0.6 \% \mathrm{w} / \mathrm{w}$ was reported as being a practical limit for manufacturing in the Seattle area. Reductions in measured toughness, $G_{\mathrm{IC}}$, and in the glass transition temperature, $T_{g}$, were reported with increasing pre-bond humidity exposures. For one adhesive, which was not identified by name, the presence of pre-bond moisture had influenced the cure kinetics of the adhesive and this had resulted in an increased size of the phase-separated rubber particles. The particle size distribution had increased from $0.40-1.6 \mu \mathrm{m}$ to $0.40-10.8 \mu \mathrm{m}$. Such an increase in the particle size of the toughening rubber-phase can potentially reduce the fracture performance of the adhesive; and indeed a reduction of up to $60 \%$ in $G_{\text {IC }}$ values was reported with one adhesive joint when the composite substrates contained 1.1\% w/w moisture prior to bonding. 


\section{Experimental}

\subsection{Introduction \& Materials}

In order to investigate the effects of pre-bond moisture on the fracture behaviour of bonded composite joints, an experimental study was performed using four different adhesives and two different composite substrates. The adhesives and substrates used in this study are listed in Table 1. All adhesives investigated were structural epoxy formulations, two were epoxyfilms (Scotch-Weld ${ }^{\mathrm{TM}}$ AF126: 3M, St. Paul, Minnesota, USA; and FM73M: Cytec Engineered Materials, Tempe, Arizona, USA) and two were epoxy-paste adhesives (ESP110: Bondmaster, Eastleigh, UK; and SI731PL: Sovereign Speciality Chemicals, Chicago, Illinois, USA). The film adhesive FM73M was carried on a polyesther matt fabric and the modified epoxy-film adhesive AF126 was reinforced with a polymeric, over weave scrim. The substrate materials employed in this study included two unidirectional CFRP laminates, firstly IM7-977/2: Cytec Engineered Materials, Tempe, Arizona, USA and secondly T300/924: Hexcel Composites, Duxford, UK. The composite substrates were manufactured in an autoclave according to the manufacturers' instructions. A unidirectional lay-up was used, with a typical panel comprising of 12 or 16 plies. When required, the panels were cut into beams with dimensions nominally $150 \mathrm{~mm} \times 20 \mathrm{~mm} \times 1.5 \mathrm{~mm}$ thick.

\subsection{Substrate conditioning}

The cured panels were stored in normal laboratory conditions $\left(23^{\circ} \mathrm{C}, 55 \% \mathrm{RH}\right)$ until required for joint manufacture or conditioning. The substrates stored in normal laboratory conditions prior to bonding are referred to here as being in the 'as received' condition. The conditioned substrates are identified via their mass fraction of absorbed water, i.e. the percentage mass of water as a proportion of the mass of the 'fully-dried' substrate (\% w/w). The substrate conditioning was achieved using the following procedure. Firstly, the substrates were initially dried under vacuum at $105^{\circ} \mathrm{C}$ for periods of up to 60 days to obtain a constant weight. The substrates were periodically removed from the oven, cooled in a desiccator and then weighed prior to returning to the oven for further drying. Weighing was performed on a balance with a resolution of $1 \times 10^{-5} \mathrm{~g}$. This process was repeated until the substrate mass stabilised, implying that it was fully-dried, i.e. possessed $0 \% \mathrm{w} / \mathrm{w}$ of water.

The two composites used in the present study absorbed different amounts of atmospheric moisture, as is illustrated in Figure 2 which shows the weight loss of 'asreceived' substrates during drying. For the IM7/977-2 composite, the 'as-received' substrates 
contained $0.49 \% \mathrm{w} / \mathrm{w}$ of moisture whereas for the T300/924 composite the equivalent value was $0.86 \% \mathrm{w} / \mathrm{w}$. It was found that all the 'as-received' substrates were 'fully-dried' after 28 days in the vacuum oven, so this was selected as the standard drying procedure applied to all the CFRP substrates in the present work. Batches of 'fully-dried' substrates were then moisture conditioned to introduce known levels of pre-bond moisture into the substrates. This was achieved by immersing the substrates in deionised water held at a constant temperature of $50{ }^{\circ} \mathrm{C}$ for periods of between 0.5 to 100 hours to allow water diffusion into the substrates to take place. Substrates were periodically removed from the bath, were thoroughly blotted dry and weighed, and were then either removed for immediate bonding or were returned to the bath for further water diffusion to occur. Non-equilibrium water concentrations from 0 to $1.0 \% \mathrm{w} / \mathrm{w}$ were attained. The substrate conditioning is summarised in Table 2 for the T300/924 substrates and in Table 3 for the IM7/977-2 substrates.

\subsection{Adhesive joint manufacture}

Adhesive joints were manufactured as DCB specimens for the purpose of performing tests to measure values of $G_{\text {IC }}$ according to the standard BS7991. All substrates were abraded with $180 / 220 \mu \mathrm{m}$ mesh alumina grit and were then wiped clean with an acetone-soaked cloth. Unless the joints were to be specifically studied in the 'as-received' condition, the substrates were then pre-conditioned as described above to control the amount of pre-bond moisture. For the epoxy-paste adhesives, the thickness of the adhesive layer was controlled using predried glass ballotini, which resulted in a bond-line thickness of $0.40+/-0.05 \mathrm{~mm}$. For the AF126 epoxy-film adhesive, a single film was applied to the joint resulting in a bondline thickness of $0.14+/-0.02 \mathrm{~mm}$. For the FM73M epoxy-film adhesive the bond-line thickness was controlled by wire shims, and two layers of adhesive were used to make the joint resulting in a bondline thickness of $0.34+/-0.06 \mathrm{~mm}$ (it is recognised that the use of two layers of film adhesive may introduce air into joint). A sheet of PTFE film was inserted into the centre of the bond-line during manufacture, to act as a crack starter. The film was $12.5 \mu \mathrm{m}$ thick, and typically extended 50mm into the joint from one end. The adhesive joints were then cured according to the manufacturer's instructions.

\subsection{Fracture testing}

The mode I DCB fracture tests were conducted according to the British Standard [7], using a screw-driven testing machine. Values of load, displacement and crack length were measured 
simultaneously for crack initiation and propagation. These data were analysed to enable a calculation of the adhesive fracture toughness, $G_{\mathrm{IC}}$, using corrected beam theory, as outlined in [20]. Values of $G_{\text {IC }}$ quoted in the present study are the mean crack propagation values. Three repeat tests were performed at each condition and the values of $G_{\text {IC }}$ reported are the average of the three mean propagation values.

\subsection{Measurement of the glass transition temperature of the cured adhesive}

To measure the glass transition temperature, $T_{g}$, of the cured adhesive in the joints, samples of adhesive were carefully removed from selected fracture surfaces using a scalpel after the fracture test and these were analysed using differential scanning calorimetry (DSC). The DSC apparatus used was a Perkin Elmer Pyris 1 system and typically about 5-10mg of sample was analysed on each run. Two heating cycles were always used, ramping at $20^{\circ} \mathrm{C} / \mathrm{min}$, with the glass transition temperature, $T_{g}$, being defined from the half width on the second heating

cycle. Values of $T_{g}$ reported here are the average of three repeat samples, each tested using the DSC cycle described above.

\subsection{Scanning electron microscopy studies}

Sections of the substrate were carefully cut from the fractured joints, mounted on an aluminium stub and sputter coated with gold prior to analysis using scanning electron microscopy. Specimens were analysed using a scanning electron microscope (Joel JSM5300) at magnifications from $\times 35$ to $\times 5000$. This gave an indication of the fracture-surface appearance and information about the degree of phase separation of the rubber-toughening phase in the adhesive.

\section{Results and Discussion}

\subsection{The 'as-received' versus 'fully- dried' joints}

The mean propagation values of $G_{\mathrm{IC}}$ and the $T_{g}$ values of the adhesive layer for joints manufactured using three of the four different adhesives and the two CFRP substrates are shown in Table 4. For the AF126 epoxy-film adhesive, only the T300/924 substrates were used to make the joints. However, for the ESP110 epoxy-paste adhesive and FM73M epoxyfilm adhesive, both the T300/924 and IM7/977-2 substrates were used. In all cases the locus of joint failure was visually assessed to be cohesive though the adhesive layer. 
The results for joints with substrates in the 'as-received' condition are compared to those with substrates in the 'fully-dried' condition in Table 4. Considering firstly the AF126 epoxy-film adhesive, there was no significant difference between the values of $G_{\mathrm{IC}}$ or $T_{g}$ for the joints manufactured with the 'as-received' as compared to the 'fully-dried' substrates. The modest increase in the value of $G_{\text {IC }}$ from $1449 \mathrm{~J} / \mathrm{m}^{2}$ to $1492 \mathrm{~J} / \mathrm{m}^{2}$ was within the calculated standard error of the data. The amount of pre-bond moisture present in the 'asreceived' T300/924 substrates (shown to be $\sim 0.86 \%$ w/w in Figure 2 ) clearly did not affect the toughness of these joints and, additionally, no reduction in the adhesive's $T_{g}$ was identified. This adhesive clearly demonstrated a very low sensitivity to pre-bond moisture in the CFRP substrates.

Considering next the results for the joints bonded with the ESP110 epoxy-paste adhesive, a significant increase in both the values of $G_{\mathrm{IC}}$ and $T_{g}$ were measured when joints were made using the 'fully-dried' CFRP substrates, as compared to joints made with 'asreceived' substrates. For the joints made with the T300/924 substrates, the $G_{\text {IC }}$ values increased from $281 \mathrm{~J} / \mathrm{m}^{2}$ to $862 \mathrm{~J} / \mathrm{m}^{2}$ and the $T_{g}$ increased from $82^{\circ} \mathrm{C}$ to $99^{\circ} \mathrm{C}$ when the substrates were 'fully-dried'. For the joints manufactured using the IM7/977-2 substrates, the value of $G_{\text {IC }}$ increased from $202 \mathrm{~J} / \mathrm{m}^{2}$ to $963 \mathrm{~J} / \mathrm{m}^{2}$, almost a five-fold increase, and the $T_{g}$ increased from $88 \mathrm{C}$ to $104{ }^{\circ} \mathrm{C}$ when 'fully-dried' substrates were employed. These results demonstrate a relatively high sensitivity of the ESP110 paste-adhesive to pre-bond moisture in the CFRP substrates. (It is apparent that the values of $G_{\mathrm{IC}}$ and $T_{g}$ for the two 'fully-dried' joints are not exactly equivalent and this was found to be due to an adhesive ageing effect, i.e. a batch-to-batch difference. Namely, the IM7/977-2 joints were bonded using a freshlymanufactured stock of paste adhesive, whereas the T300/924 joints were bonded with adhesive that had been maintained in a freezer for 12 months. The cold storage had thus aged the adhesive, possibly by allowing the ingress of moisture as discussed in Section 2.2, or possibly due to an advancement of the cure, and this led to a loss of toughness and adhesive $\left.T_{g}.\right)$

Considering finally the results for the joints bonded with the FM73M epoxy-film adhesive, it was shown that there was no significant difference, when taking into consideration the standard error in the data, between the values of $G_{\text {IC }}$ for the joints using the 'as-received' as compared to 'fully-dried' substrates, although a reduction in $T_{g}$ was evident when pre-bond moisture was present. 


\subsection{The moisture-conditioned joints}

Following these initial results, two adhesives were selected for a more detailed study. The ESP110 was selected because this adhesive had demonstrated a strong sensitivity in terms of both toughness and $T_{g}$ to pre-bond moisture in the CFRP substrates; whereas FM73M was selected because it had demonstrated a dependence in $T_{g}$, but not in toughness.

The results for the moisture-conditioned joints bonded with the ESP110 pasteadhesive are shown in Figure 3, where the CFRP substrates had absorbed up to about $0.9 \%$ w/w of moisture prior to joint manufacture. The results for the joints manufactured using substrates in the 'as-received' (AR) condition are also shown in Figure 3 for reference, and these are the filled data points. It is seen that when the 'fully-dried' substrates were bonded, the values of $G_{\mathrm{IC}}$ were always in the range of 860 to $963 \mathrm{~J} / \mathrm{m}^{2}$, depending on the age of the adhesive stock used as previously discussed. As the level of pre-bond moisture was increased, the values of $G_{\mathrm{IC}}$ decreased, reaching a lower-bound value of approximately 100 $\mathrm{J} / \mathrm{m}^{2}$ at a pre-bond moisture content of about $0.5 \% \mathrm{w} / \mathrm{w}$. It is seen that while the 'fully-dried' and the moisture controlled joints all fall onto the same trend-line drawn through the data in Figure 3, this is not the case for the joints made with CFRP substrates in the 'as-received' condition. This is likely to be the result of the different water distributions between the joints in the 'as-received' condition and the moisture-conditioned joints. The joints conditioned via water submersion would have a saturated surface region of composite substrate and a relatively drier interior. The substrates in the 'as-received' condition absorbed pre-bond moisture over a much longer duration ( $>3$ months) and would thus have attained a more even distribution of water through their thickness. Thus, the water molecules in the moistureconditioned joints were closer to the adhesive/substrate interface and was therefore likely to interact more readily with the adhesive prior to full cure. Hence, for a given pre-bond moisture content, the moisture-conditioned joints could be anticipated to have a lower toughness than joints in the as-received condition, as is indeed observed here. These values of $G_{\mathrm{IC}}$ are shown as a function of the $T_{g}$ of the adhesive layer in Figure 4. A linear correlation was found between the values of $G_{\mathrm{IC}}$ and $T_{g}$, over most of the $T_{g}$ range. Most noticeably, the joints in the 'as-received' condition, with one exception, fell on the same line as the moisturecontrolled joints, indicating unusually that, for this joint system, the value of the $T_{g}$ was an excellent predictor of toughness. Some scatter in the data at the very low values of toughness was noted, and this was probably due to the presence of large voids in the adhesive layer. As 
will be discussed further later, such voids become very prominent when high levels of prebond moisture were introduced into the CFRP substrates.

The equivalent results for the joints bonded with the FM73M epoxy-film adhesive are shown in Figures 5 and 6 . The data in Figure 5 indicate that, over the range studied and within the experimental scatter, there was no dependence of the values of $G_{\text {IC }}$ upon the level of pre-bond moisture in the CFRP substrates. Further, Figure 6 shows that when the values of $G_{\text {IC }}$ were plotted as a function of $T_{g}$, then no relationship was evident between the values of $G_{\text {IC }}$ and $T_{g}$. Thus, no dependence of the toughness upon the level of pre-bond moisture in the CFRP substrates, nor upon the value of the $T_{g}$ of the adhesive, was observed with the FM73M adhesive.

The effects of pre-bond moisture on the joints bonded with a second epoxy-paste adhesive, the two-part system, SI731PL, was also studied. IM7/977-2 substrates were moisture conditioned to $0,0.15$ and $0.3 \% \mathrm{w} / \mathrm{w}$ and DCB joints were then manufactured and tested to measure values of $G_{\mathrm{IC}}$ and $T_{g}$. For these joints the values of $G_{\mathrm{IC}}$ increased with increasing levels of pre-bond moisture, rising from $1950+/-500 \mathrm{~J} / \mathrm{m}^{2}$ at $0 \% \mathrm{w} / \mathrm{w}$ to $2800+/-$ $240 \mathrm{~J} / \mathrm{m}^{2}$ at $0.3 \% \mathrm{w} / \mathrm{w}$ water in the CFRP substrates. Over this range, the $\mathrm{T}_{\mathrm{g}}$ decreased from $111+/-9^{\circ} \mathrm{C}$ to $89+/-1^{\circ} \mathrm{C}$.

\subsection{Fractographic studies of the joints bonded using the ESP110 adhesive}

In all cases the locus of joint failure was visually cohesive though the adhesive layer. Nevertheless, scanning electron microscopy was undertaken on the fracture surfaces of the different joints bonded with the ESP110 epoxy-paste adhesive in order to investigate whether any differences in the fracture surface morphology and voiding had occurred when the levels of pre-bond moisture in the composite substrates were increased.

Figures 7 (a) and (b) show a typical fracture surface resulting from a joint made with 'fully-dried' IM7/977-2 composite substrates (0\% w/w water). Figure 7(a) was taken at a magnification of $\times 35$ and Figure $7(b)$ at $\times 5000$. Features which are typical of a rubbertoughened adhesive undergoing relatively ductile fracture, i.e. showing rubber particle cavitation and with shear yielding, are clearly evident at the higher magnification. Whilst some voids are evident at the lower magnification, as seen in Figure 7(a), these were not considered to be of particular significance. 
Figures 8 (a) and (b) show a typical fracture surface resulting from a joint with IM7/977-2 composite substrates bonded in the 'as-received' condition. The appearance of this fracture surface is somewhat different. Here the surface, whilst revealing the presence of rubber particles at the higher magnification, did not exhibit the characteristics of extensive particle cavitation and/or shear yielding which were particularly evident in Figure 7 (b). Further, at the lower magnification the presence of larger voids was detected. However, it is unlikely that these voids alone would have resulted in the severe loss of toughness observed for these joints and, of course, would not account for the reduction in the $T_{g}$ of the adhesive.

Finally, Figures 9 (a) and (b) shows a typical fracture surface for a joint in which the substrates had been moisture conditioned to $0.4 \%$ w/w. Figure 9(a), at the lower magnification, revealed the presence of very enlarged voids, which are probably steamgenerated cavities where the adhesive had been displaced by steam emitted from the substrate during the adhesive cure at $150^{\circ} \mathrm{C}$. This observation is consistent with the major reduction in measured joint toughness, see Figure 3. Figure 9(b) at the higher magnification depicts a smooth surface with few of the features typically present following ductile adhesive fracture. Thus, as for Figure 8b, evidence of the rubber-phase separating from the epoxy matrix can be seen in Figure 9(b), but this fracture surface has a distinctly different appearance to that shown in Figure 7(b).

In previous work [8] it had been suggested that the main effect of the pre-bond moisture might be to inhibit the phase separation of the rubber during the curing of the adhesive, which leads to the formation of the rubber particles which impart a high level of toughness to the adhesive. This would lead to the initially-soluble rubber remaining within the epoxy phase after the adhesive had been cured. This scenario would be expected to reduce both the toughness, $G_{\mathrm{IC}}$, and $T_{g}$ of the adhesive simultaneously, as indeed was observed (see Figure 3). However, the micrographs shown in Figures 7 to 9 certainly suggest the presence of phase-separated rubber particles, so this theory may be discounted.

Thus, whilst the fracture surface studies do not reveal the cause of the reduction in toughness due to the pre-bond moisture in the substrates, they do support the observation that an embrittlement of the adhesive indeed occurred. Also, that, at the very highest pre-bond moisture concentrations, the adhesive contained relatively large voids. 


\subsection{Discussion of the results}

The results reported here indicate that the severe reduction in the value of the adhesive fracture energy measured for joints bonded with the ESP110 epoxy-paste adhesive when prebond moisture was present in the composite substrates was not a general phenomena. The two epoxy-film adhesives (AF126 and FM73M) demonstrated a level of toughness independent of pre-bond moisture in the joints. Further, the second epoxy-paste adhesive (i.e. SI731PL) showed an increase in the adhesive fracture energy as the level of pre-bond moisture in the CFRP substrates was increased from 0 to $0.3 \mathrm{w} / \mathrm{w}$.

Whilst it is clear that composite substrates should be dried prior to adhesive bonding, as observed by Sage et al [12] and Parker [13], the fact that some adhesives have such extreme sensitivity to pre-bond moisture is of concern, as industrial standards for composite drying prior to bonding are not very stringent, i.e. they typically specify only about 60 minutes in an air circulating oven at between 60 to $80^{\circ} \mathrm{C}$ [21]. However, for example, in the present study it took 28 days under vacuum at $105^{\circ} \mathrm{C}$ to completely dry the 'as-received' composite, which had only been stored in the laboratory for between 3 and 6 months prior to use.

In the present work, the possibility that water had interfered with the complete phase separation of the rubber particles in the moisture-sensitive ESP110 adhesive, so preventing the second, toughening phase from forming, has been discounted. On the other hand, certainly the creation of relatively large voids in the adhesive, at very high levels of pre-bond moisture, was associated with very low toughness values. However, although the creation of voids in the bondline was considered to be a significant factor, it cannot alone fully explain the observed loss of toughness and $T_{g}$ of the adhesive. Therefore, there appears to be an embrittlement in addition to these noted above for the ESP110 adhesive, which is caused by the presence of pre-bond moisture in the composite substrates diffusing into the adhesive layer during joint manufacture. The mechanism behind this embrittlement phenomenon is discussed in detail in a subsequent paper [10]. 


\section{Conclusions}

The toughness of an epoxy-paste adhesive (i.e. ESP110) was found to highly sensitive to prebond moisture present in composite CFRP substrates prior to adhesive bonding. This moisture diffused into the adhesive layer during joint manufacture and led to a significant reduction in toughness of the adhesive, which was also accompanied by a significant reduction in $T_{g}$ of the adhesive. These effects were shown to be independent of the composite material used, since the important parameter was the concentration of water present in the substrate material at the time of curing the adhesively-bonded joint. In contrast, two epoxyfilm adhesives (AF126 and FM73M) were found to be far less sensitive to pre-bond moisture. Further, the toughness of a second epoxy-paste adhesive (i.e. SI731PL) was shown actually to increase somewhat when $0.35 \% \mathrm{w} / \mathrm{w}$ water was absorbed by the composite substrates prior to joint manufacture. These observations clearly demonstrate that the effects of pre-bond moisture present in the composite CFRP substrates, prior to adhesive bonding, are complex and are very dependent upon the adhesive being employed.

For the moisture-sensitive ESP110 adhesive, the void content was observed to increase with increasing levels of pre-bond moisture in the CFRP substrates. Scanning electron microscopy studies revealed that the loss of toughness and $T_{g}$ were associated with a change in the appearance of the fracture surfaces. Several interesting observations were made. Firstly, the phase separation of the toughening rubber-phase did still occur when the joints were made using either moisture-containing or 'fully-dried' substrate conditions. Secondly, however, subsequent cavitation of the rubber particles and shear yielding of the epoxy were only observed when 'fully-dried' substrates were employed. Thirdly, that, at the very highest pre-bond moisture concentrations, the adhesive contained relatively large voids.

It was shown that to attain 'fully-dried' composite substrates, it typically took 28 days of drying under vacuum at $105^{\circ} \mathrm{C}$ to remove all the absorbed moisture from the composite CFRP substrates. Such rigorous drying conditions were thus necessary to dry fully the composite substrates and avoid the potential harmful effects of pre-bond moisture during subsequent joint manufacture. Finally, it is recommended that, unless the performance of an adhesive when bonding composite substrates containing absorbed moisture is well understood, then composite substrates should be 'fully-dried' prior to adhesive bonding. 


\section{Acknowledgements}

We wish to thank Bondmaster (UK) and Cytec Engineered Materials for material supply.

For funding, we wish to thank the Singapore Government (A-Star scheme) for supporting WST and the EPSRC under grant EP-C547888-1. We would like also to thank Mr. J. Bishopp for useful discussions.

\section{References}

1. Comyn, J., Durability of Structural Adhesives, Ed. Kinloch, A.J., (Applied Science Publishers: London and New York, 1983). Ch. 3, pp. 85-129.

2. $\quad$ Gledhill, R.A. and Kinloch, A.J., J. Adhes. 6, 315-330 (1974).

3. Kinloch, A.J., Adhesion \& Adhesives: Science \& Technology, (London \& New York: Chapman Hall, 1987). p.441.

4. Hart-Smith, L.J., Int. J. Mech. Sci. 19, 181-191 (1999).

5. Hart-Smith, L.J. (Proceedings of the 26th Annual Meeting of the Adhesion Society: Myrtle Beach, SC, USA: The Adhesion Society, 2003).

6. Hart-Smith, L.J. Report MIL-HDBK-17 \& FAA Meeting, Seattle, Washington, USA, (2004).

7. BS 7991, British Standards Institution, London (2001).

8. Blackman, B.R.K., Kinloch, A.J. and Paraschi, M., J. Maters Sci. Lett. 20, 265-267 (2001).

9. Blackman, B.R.K., Kinloch, A.J., and Teo, W.S. (Proceedings of the 26th Annual Meeting of the Adhesion Society: Myrtle Beach, SC, USA: The Adhesion Society, 2003).

10. Blackman, B.R.K., Johnsen, B.B., Kinloch, A.J., and Teo, W.S, to be submitted 2008.

11. Kohan, M.I., Nylon plastics handbook, (Carl Hanser Verlag, 1995).

12. Sage, G.N., and Tiu, W.P., Composites 13, 228-232 (1982).

13. Parker, B.M., Composites 14 (3) 226-232 (1983).

14. Robson, J.E., Matthews, F.L., and Kinloch, A.J., Compos. Sci. \& Tech 52, 235-246 (1994).

15. Dodiuk, H., Drori, L., and Miller, J., J. Adhes. 17, 33-44 (1984).

16. Dodiuk, H., Drori, L., and Miller, J., J. Adhes. 19, 1-13 (1985).

17. Buchman, A., Dodiuk, H., and Kenig, S., J. Adhes. 24, 1229-1243 (1987).

18. van Voast, P.J. (Proceedings of SAMPE, 2002). 
19. van Voast, P.J. and Barnes, S.R., (Proceedings of the 28th Annual Meeting of the Adhesion Society, Mobile, AL, USA: The Adhesion Society, 2005).

20. Blackman, B.R.K., Kinloch, A.J., Paraschi, M., and Teo, W.S., Int. J. Adhes \& Adhes 23, 293-305 (2003).

21. SAE-ARP-4977 (Drying of thermosetting composite materials). 
TABLES

Table 1 . The adhesive and substrate materials used in the study

\begin{tabular}{ll}
\hline Adhesives & Cure cycle (Temperature / time) \\
\hline AF126 epoxy-film & $90^{\circ} \mathrm{C} / 90$ mins $+120^{\circ} \mathrm{C} / 120$ mins \\
ESP110 epoxy-paste (1 part formulation) & $150^{\circ} \mathrm{C} / 45 \mathrm{mins}$ \\
FM73M epoxy-film & $120^{\circ} \mathrm{C} / 60 \mathrm{mins}$ \\
SI731PL epoxy-paste (2 part formulation) & $127^{\circ} \mathrm{C} / 30$ mins \\
\hline CFRP substrates & \\
IM7/977-2 & 12 ply unidirectional composite $\left[0^{\circ}\right]_{12}$ \\
T300/924 & 16 ply unidirectional composite $\left[0^{\circ}\right]_{16}$ \\
\hline
\end{tabular}

Table 2: Conditioning of the 16-ply T300/924 composite substrates

\begin{tabular}{|c|c|c|}
\hline $\begin{array}{c}\text { Condition } \\
(\% \mathrm{w} / \mathrm{w}) \text { water }\end{array}$ & $\begin{array}{l}\text { Conditioning time under } \\
\text { vacuum at } 105^{\circ} \mathrm{C} \text { (days) }\end{array}$ & $\begin{array}{l}\text { Conditioning time in water } \\
\text { immersion at } 50^{\circ} \mathrm{C} \text { (hours) }\end{array}$ \\
\hline 0 (Fully-dried) & 28 & - \\
\hline 0.05 & 28 & 0.5 \\
\hline 0.10 & 28 & 8.5 \\
\hline 0.20 & 28 & 11.25 \\
\hline 0.30 & 28 & 16.75 \\
\hline 0.40 & 28 & 25.25 \\
\hline 0.60 & 28 & 56.5 \\
\hline 0.80 & 28 & 97.25 \\
\hline As-received & $\begin{array}{l}\text { Held at } 23^{\circ} \mathrm{C}, 55 \mathrm{RH} \text { for } \\
>3 \text { months }\end{array}$ & - \\
\hline
\end{tabular}

Note: $(\% \mathrm{w} / \mathrm{w}=)$ (weight water $/$ weight substrate $) \times 100 \%$ 
Table 3: Conditioning of the 24-ply IM7/977-2 composite substrates

\begin{tabular}{|c|c|c|}
\hline $\begin{array}{c}\text { Condition }(\% \mathrm{w} / \mathrm{w}) \\
\text { water }\end{array}$ & $\begin{array}{c}\text { Conditioning time under vacuum } \\
\text { at } 105^{\circ} \mathrm{C} \text { (days) }\end{array}$ & $\begin{array}{l}\text { Conditioning time in water } \\
\text { immersion at } 50^{\circ} \mathrm{C} \text { (hours) }\end{array}$ \\
\hline 0 (Fully-dried) & 28 & - \\
\hline 0.15 & 28 & 13.25 \\
\hline 0.30 & 28 & 40.75 \\
\hline
\end{tabular}

As-received $\quad$ Held at $23^{\circ} \mathrm{C}, 55 \mathrm{RH}$ for $>3$ months

Table 4 Values of $G_{I C}$ and $T_{g}$ of the various adhesives used to bond the CFRP substrates in either the as-received or fully dried $(0 \% \mathrm{w} / \mathrm{w})$ condition.

\begin{tabular}{|c|c|c|}
\hline $\begin{array}{l}\text { Adhesive } \\
\text { Substrate (condition) }\end{array}$ & $\begin{array}{c}G_{I C} \\
\left(\mathrm{~J} / \mathrm{m}^{2}\right)\end{array}$ & $\begin{array}{c}T_{g} \\
\left({ }^{0} \mathrm{C}\right)\end{array}$ \\
\hline \multicolumn{3}{|l|}{ AF126 } \\
\hline T300/924 (as-rec’d) & $1450 \pm 110$ & $101 \pm 3$ \\
\hline T300/924 (0\% w/w) & $1490 \pm 80$ & $100 \pm 3$ \\
\hline \multicolumn{3}{|l|}{ ESP110 } \\
\hline T300/924 (as-rec’d) & $280 \pm 50$ & $82 \pm 1$ \\
\hline T300/924 (0\% w/w) & $860 \pm 20$ & $99 \pm 1$ \\
\hline IM7/977-2 (as rec’d) ${ }^{\dagger}$ & $200 \pm 20$ & $88 \pm 1$ \\
\hline IM7/977-2 (0\% w/w) & $960 \pm 20$ & $104 \pm 1$ \\
\hline \multicolumn{3}{|l|}{ FM73M } \\
\hline T300/924 (as-rec’d) & $3280 \pm 110$ & $92 \pm 1$ \\
\hline T300/924 (0\% w/w) & $3630 \pm 320$ & $101 \pm 1$ \\
\hline IM7/977-2 (as-rec’d) & $3320 \pm 100$ & $93 \pm 2$ \\
\hline IM7/77-2 (0\% w/w) & $3180 \pm 230$ & $102 \pm 1$ \\
\hline
\end{tabular}

Notes: $\left(^{\dagger}\right)$ Obtained in the round-robin study [20]. Values of $G_{I C}$ are mean propagation values and are the average obtained in three repeat tests. Errors are the standard error of the data. 


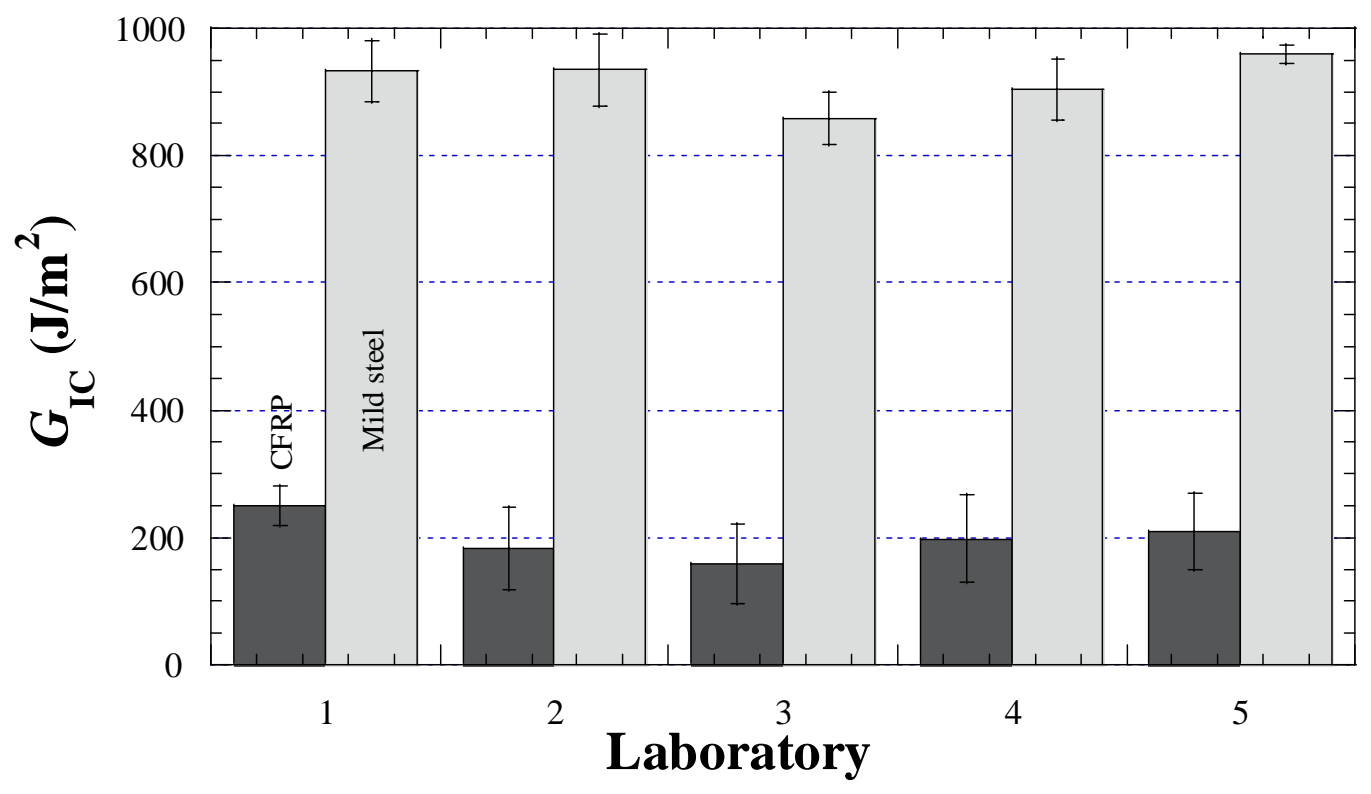

Figure 1. Values of $G_{\text {IC }}$ measured in five test laboratories for joints with either CFRP or mild steel substrates bonded with the general-purpose epoxy-paste ESP110 adhesive. (Height of columns are the mean, and error bars the standard deviation (SD) of four repeat tests in each laboratory participating in the round-robin (coded 1-5)). 


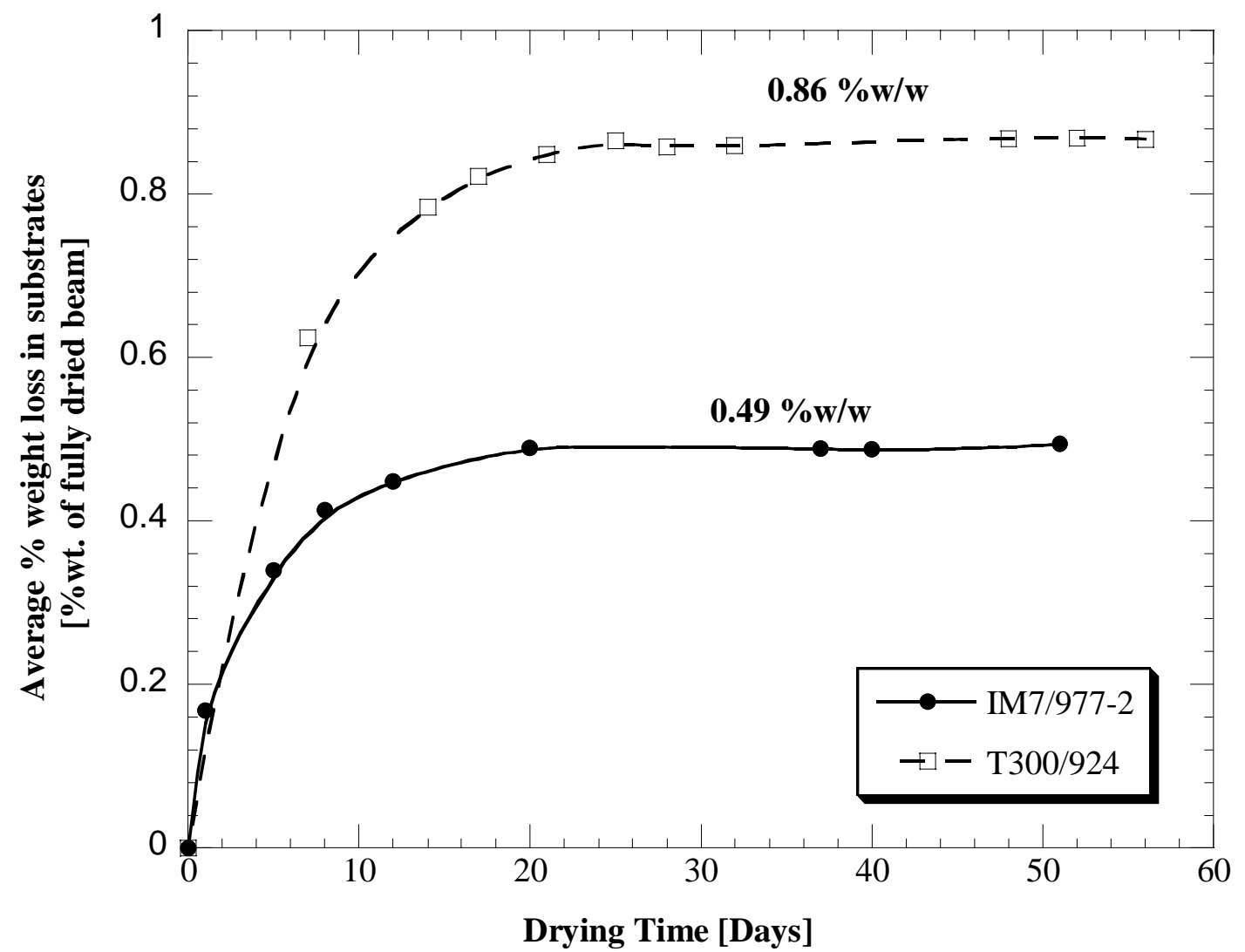

Figure 2. The average weight loss of 'as-received' substrates (expressed as a percentage of the weight of the 'fully-dried' substrates) during $105^{\circ} \mathrm{C}$ drying under vacuum for the T300/924 and the IM7/977-2 CFRP beams. 


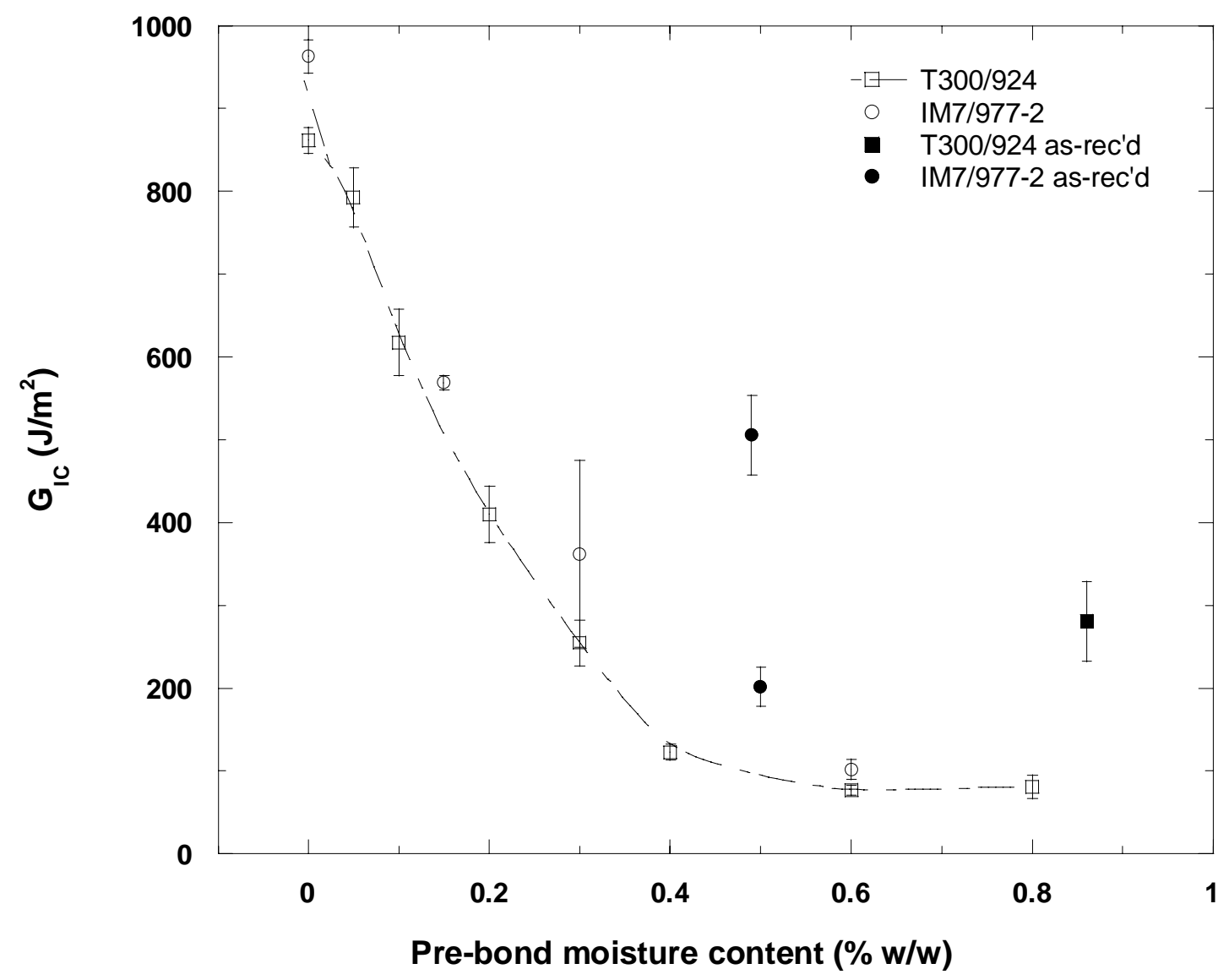

Figure 3. Values of $G_{\mathrm{IC}}$ versus pre-bond moisture content for joints bonded using the generalpurpose epoxy-paste ESP110 adhesive. Data are shown for both the T300/924 and the IM7/977-2 substrates. (Data points are the mean and error bars the SD of three repeat tests at each condition.) 


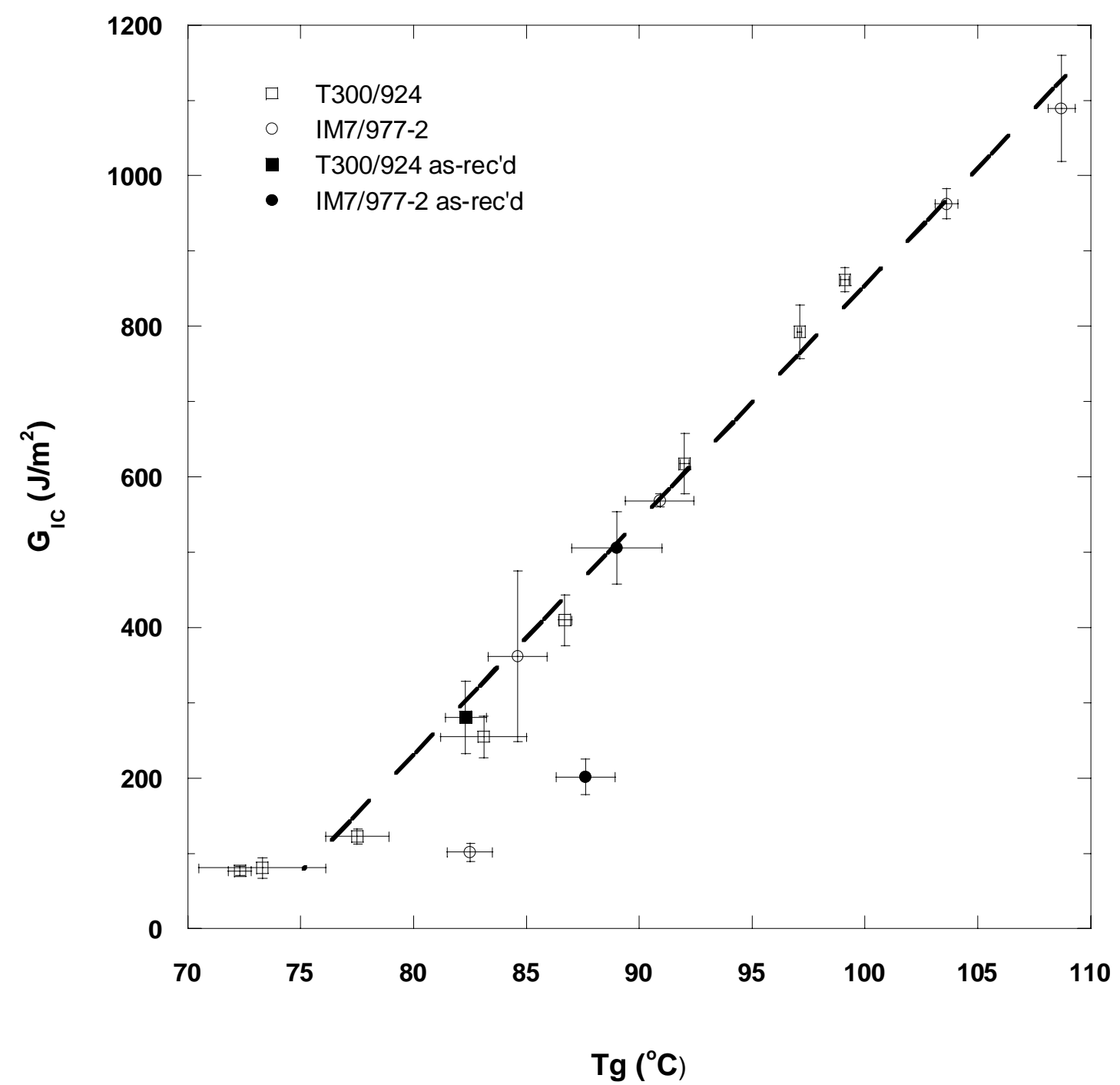

Figure 4. Values of $T_{g}$ versus pre-bond moisture content for samples of adhesive removed from joints bonded using the general-purpose epoxy-paste ESP110 adhesive. Data are shown for both the T300/924 and the IM7/977-2 substrates. (Data points are the mean and error bars the SD of three repeat analyses at each condition.) 


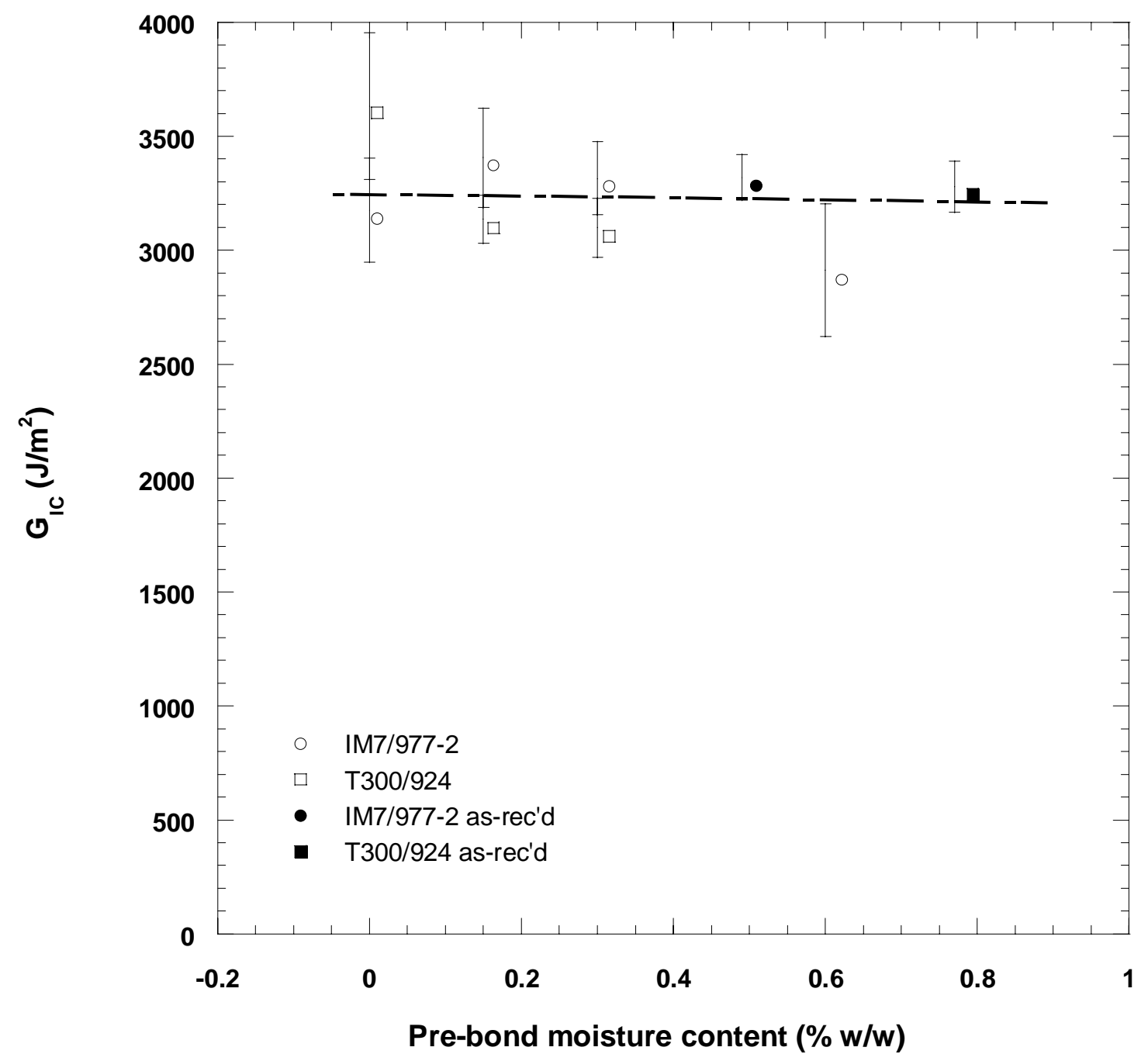

Figure 5. Values of $G_{\text {IC }}$ versus pre-bond moisture content for joints bonded using the FM73M adhesive. Data are shown for both the T300/924 and the IM7/977-2 substrates. (Data points are the mean and error bars the SD of three repeat tests at each condition.) 


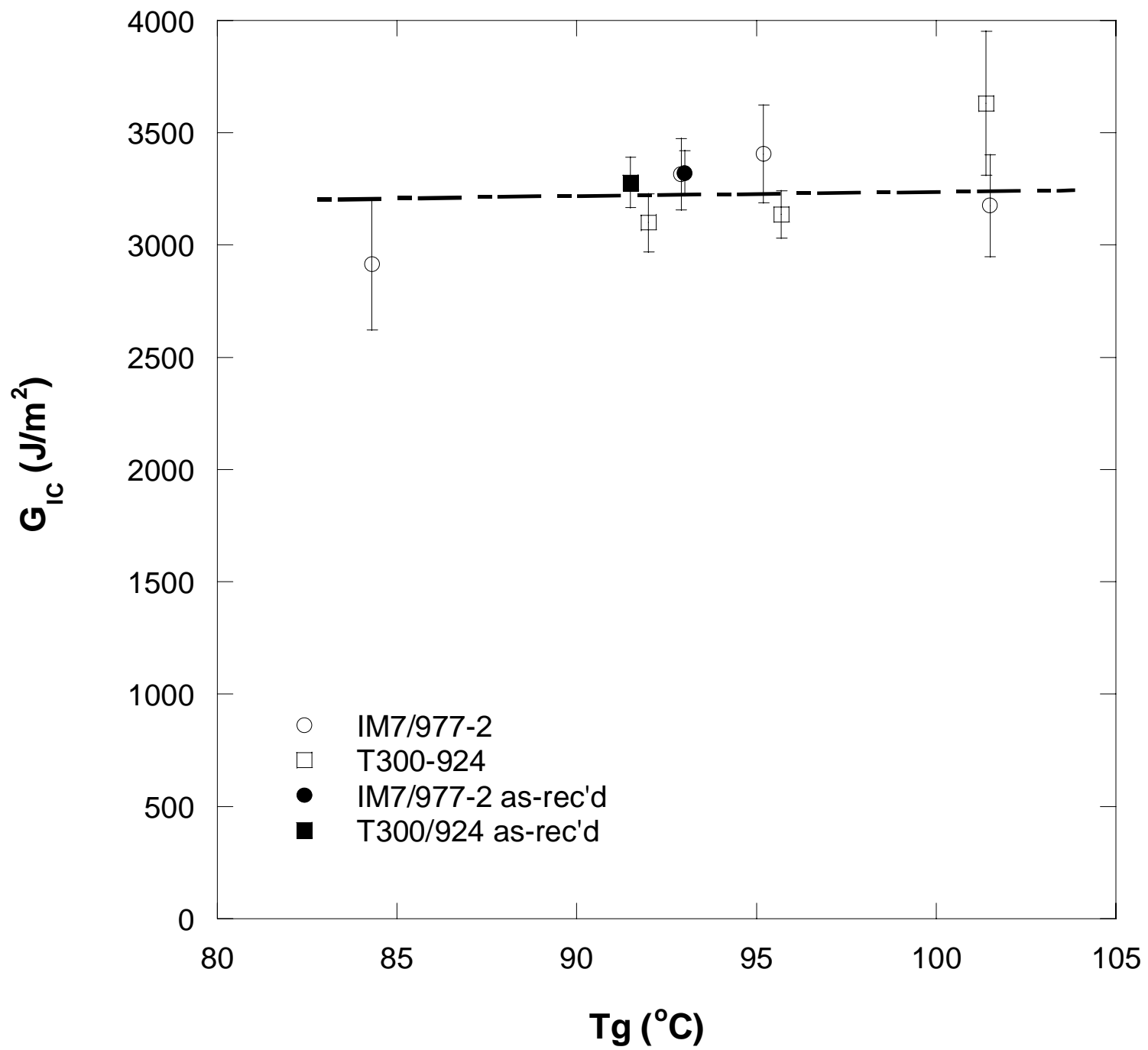

Figure 6. Values of Tg versus pre-bond moisture content for samples of adhesive removed from joints bonded using the FM73M adhesive. Data are shown for both the T300/924 and the IM7/9772 substrates. (Data points are the mean and error bars the SD of three repeat analyses at each condition.) 


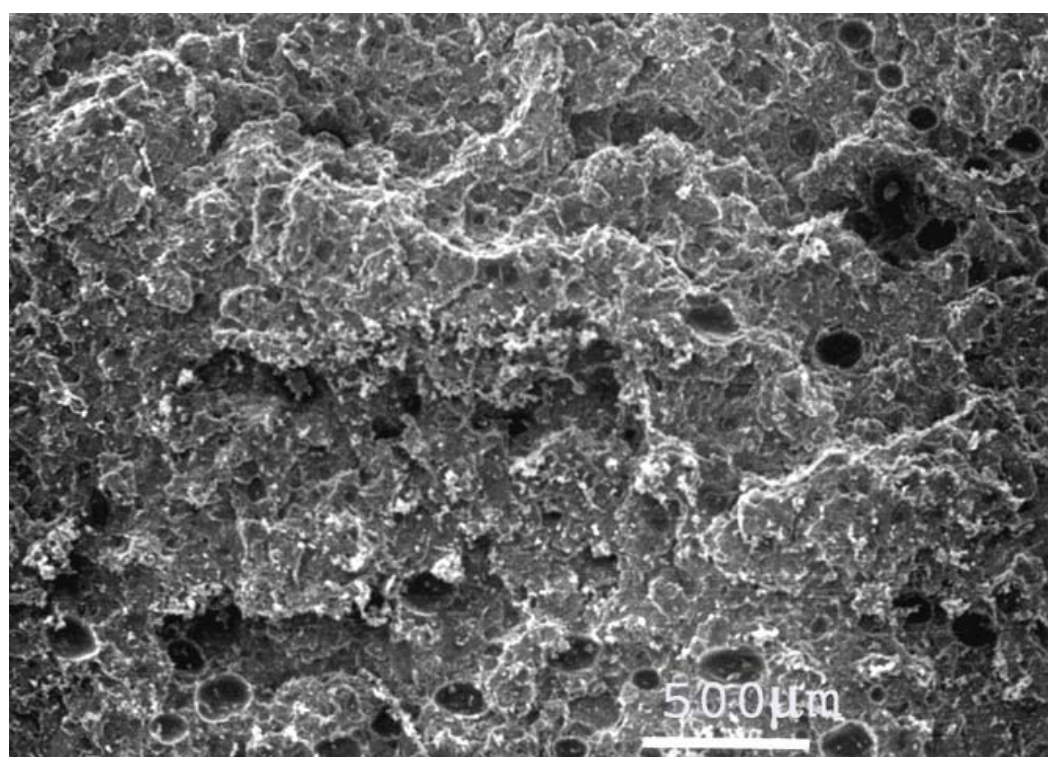

Figure 7(a) Cohesive fracture surface morphology of the ESP110 epoxy-paste adhesive when bonding the IM7/977-2 composite (substrates in the fully-dried condition). Scale bar $=500$ microns.

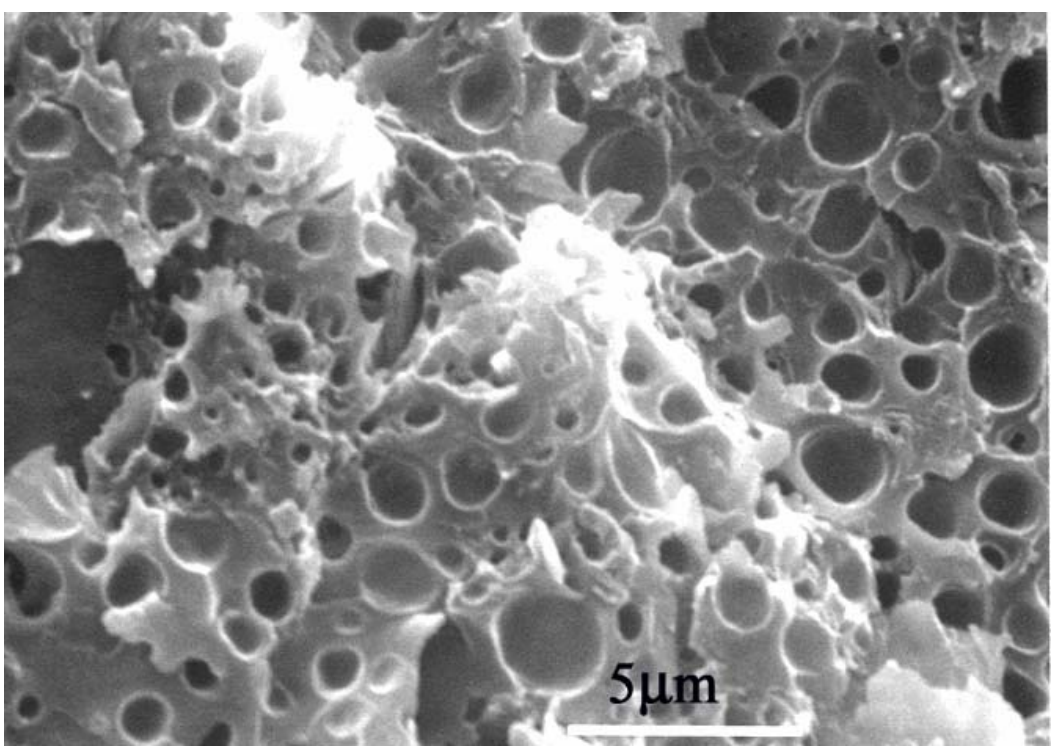

Figure 7(b) Cohesive fracture surface morphology of the ESP110 epoxy-paste adhesive when bonding the IM7/977-2 composite (substrates in the fully-dried condition). Scale bar $=5$ microns. 


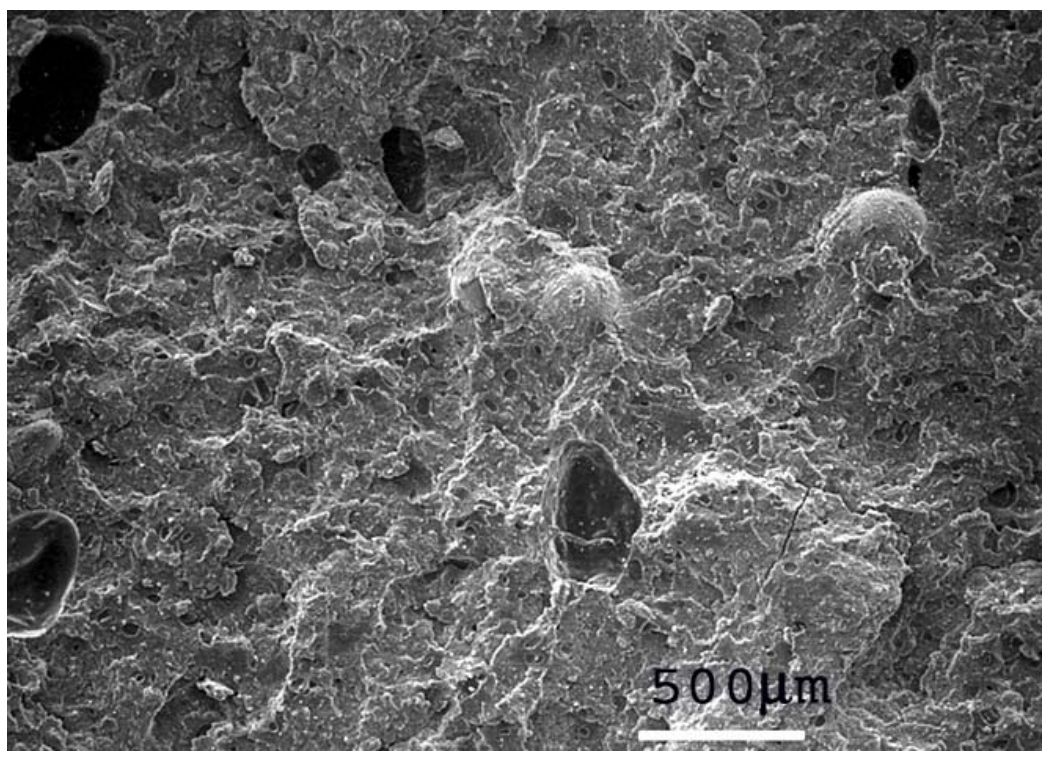

Figure 8(a) Cohesive fracture surface morphology of the ESP110 epoxy-paste adhesive when bonding the IM7/977-2 composite (substrates in the as-received condition). Scale bar $=500$ microns.

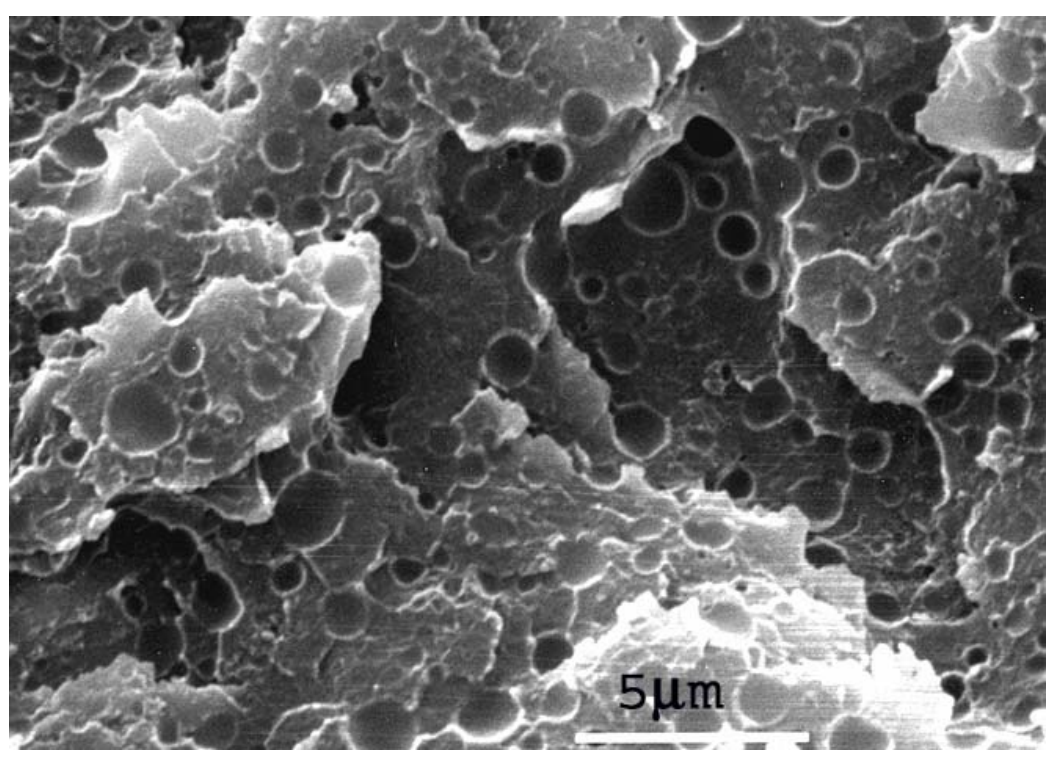

Figure 8(b) Cohesive fracture surface morphology of the ESP110 epoxy-paste adhesive when bonding the IM7/977-2 composite (substrates in the as-received condition). Scale bar $=5$ microns. 


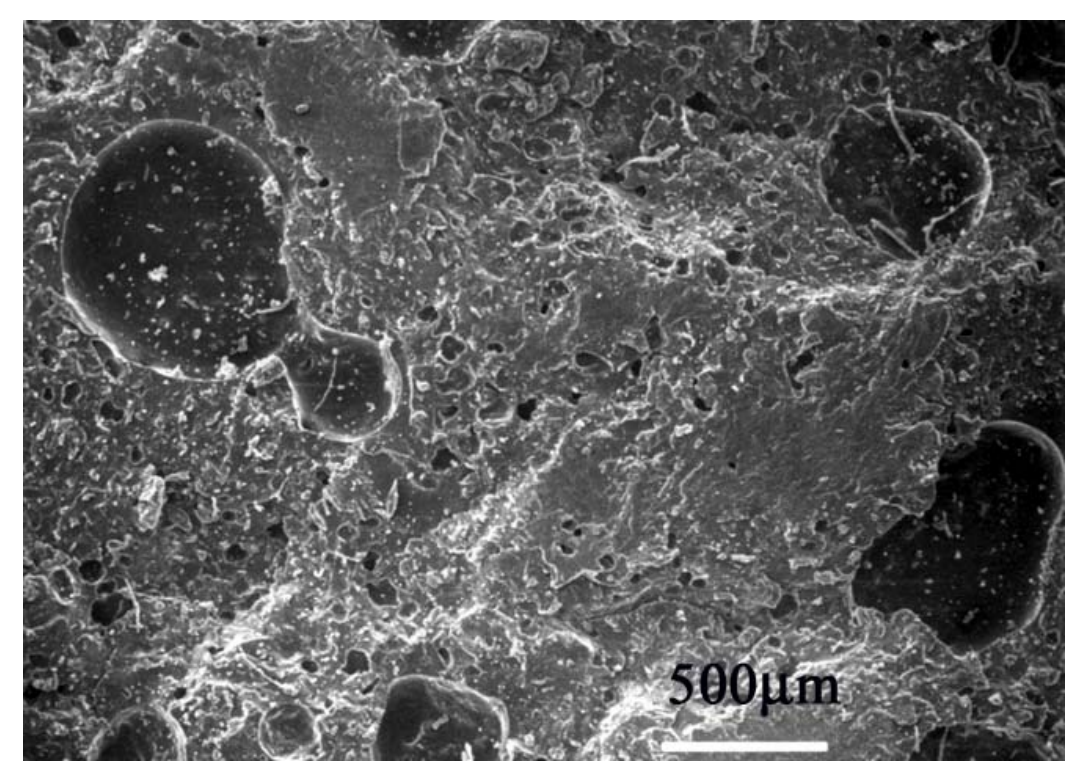

Figure 9(a) Cohesive fracture surface morphology of the ESP110 epoxy-paste adhesive when bonding the IM7/977-2 composite (substrates conditioned to $0.4 \% \mathrm{w} / \mathrm{w}$ pre-bond moisture). Scale bar $=500$ microns.

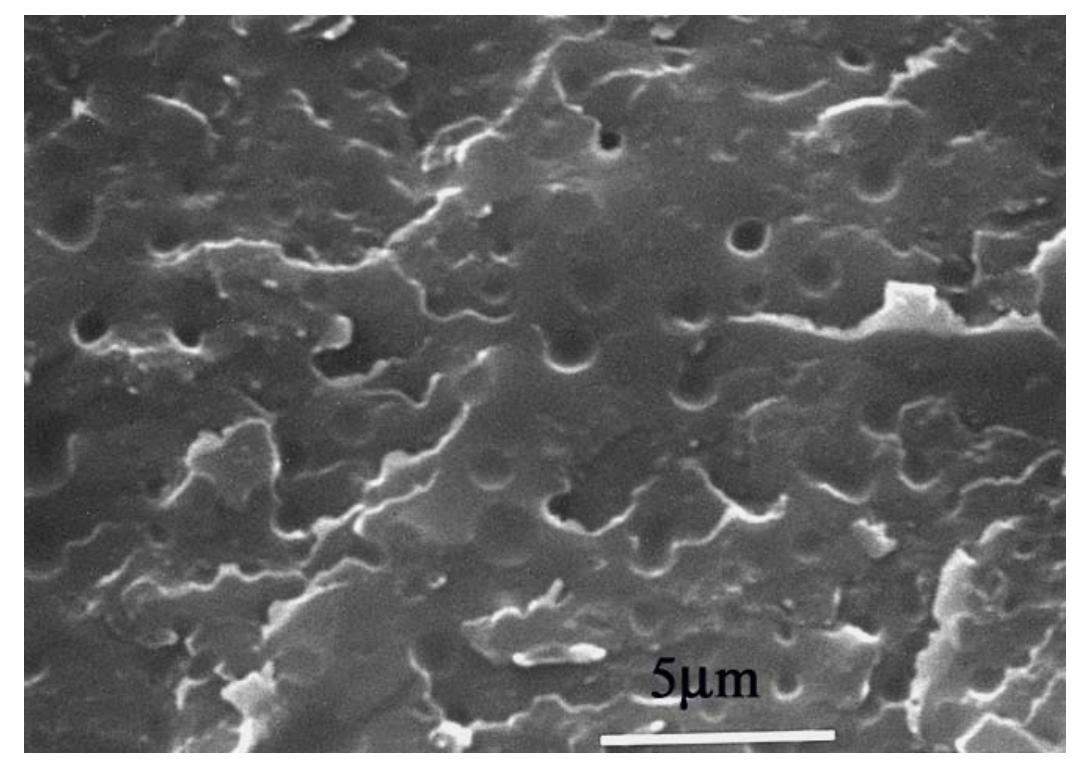

Figure 9(b) Cohesive fracture surface morphology of the ESP110 epoxy-paste adhesive when bonding the IM7/977-2 composite (substrates conditioned to $0.4 \% \mathrm{w} / \mathrm{w}$ pre-bond moisture). Scale bar $=5$ microns. 